\title{
Microstructural and hydro-mechanical behaviour of bentonite pellets and powder mixtures
}

\author{
Arisleidy Mesa Alcantara ${ }^{1, *}$, Enrique Romero ${ }^{1}$, Nadia Mokni ${ }^{2}$, and Sebastià Olivella ${ }^{1}$ \\ ${ }^{1}$ Universitat Politècnica de Catalunya, CIMNE, Barcelona, Spain \\ ${ }^{2}$ Institut de Radioprotection et de Sûreté Nucléaire (IRSN), 92260 Fontenay-aux-Roses, France
}

\begin{abstract}
Binary mixtures of high-density MX-80 bentonite pellets (80\%) and bentonite powder (20\%) at hygroscopic water content have been recently considered as an alternative engineered barrier system for the long-term disposal of radioactive wastes. These mixtures display a dry density of around $1.49 \mathrm{Mg} / \mathrm{m} 3 \mathrm{on}$ pouring and present components with multi-modal pore size distributions that significantly evolve during the hydro-mechanical paths. To better understand the hydro-mechanical behaviour of this multiple porosity mixture, the contribution initially focuses on describing the initial state, as well as the main microstructural features determined by mercury intrusion porosimetry tests for the mix and each of the components (pellets and powder). Afterwards, hydro-mechanical results of both components and the mixture are presented. The hydraulic results focus on the water retention and water permeability, while the mechanical tests concentrate on the compressibility properties on loading.
\end{abstract}

\section{Introduction and background}

Bentonite-based mixtures have been recently proposed as candidate sealing materials for high-level radioactive wastes deep geological disposal for high-level radioactive wastes [1-3]. Different configurations of high-density bentonite pellets have been considered in the past, such as Febex bentonite pellets with different sizes [2] and mixtures of FoCa high-density pellet (50\%) and bentonite powder (50\%) [1]. One of the main advantages of pellet mixtures, besides the clear benefits in terms of easiness of emplacement and reduced gaps between the rock and the seal, is the decrease of the compaction effort required to achieve the target dry density.

The French Institute for Radiological Protection and Nuclear Safety (IRSN) has been recently involved in the 'Vertical Sealing System' (VSEAL) project that studies the long-term hydration process of an engineered barrier based on granulated/powder MX- 80 bentonite and the impact of gas migration at different hydraulic states. Once installed in the repository, this sealing material will be affected by coupled hydro-mechanical (HM) processes and gas migration: hydration under constant volume due to water infiltration from the geological barrier and the corresponding increase in confining stresses (swelling pressure); and at long term, gas pressurisation and migration induced primarily by metallic corrosion of the canisters.

In the VSEAL project, the mixture, constituted by high-density bentonite pellets ( $80 \%$ dry mass ratio) and bentonite powder obtained from crushed pellets, displays an emplacement dry density of $1.49 \mathrm{Mg} / \mathrm{m}^{3}$ on pouring.
This heterogeneous mixture will undergo important pore size distribution changes on hydration, which will have consequences on the short-term HM behaviour of the material and its long-term response to gas migration. It is therefore essential to understand these $\mathrm{HM}$ behavioural features when assessing the overall repository safety.

This paper will focus on different HM aspects of the mixture and its components. It starts by describing the main properties of the components, not only from a macroscopic approach (particle size distribution and initial state) but also from a microstructural viewpoint (pore size distribution). Afterwards, the main hydraulic properties (water permeability and water retention curves) and mechanical properties (compressibility on loading at constant water content) are described for the components and the mixture.

\section{Characterisation and initial states of the components and mixture}

Table 1 presents the main properties of MX-80 bentonite, which is the material used to prepare the components (pellets and powder) of the mixture, compared to other active clays [4-6]. MX-80 presents a montmorillonite content $\geq 80 \%$, a total specific surface of $523 \mathrm{~m}^{2} / \mathrm{g}$, and the major exchangeable cation is $\mathrm{Na}^{+}$ [7].

Pellets were compacted in Laviosa-MPC (France) at low water content $w=5-7 \%$ (oven-drying at $105^{\circ} \mathrm{C}$ during $48 \mathrm{~h}$ ) to target dry density $\rho_{d}$ pell $=1.99-2.12$ $\mathrm{Mg} / \mathrm{m}^{3}$ [3]. The variations in dry density were associated 
with some fissuring observed on the pellets' surface and to expansion related to water absorption. The initial total suction -measured with WP4 chilled-mirror dewpoint psychrometer- was $s=163 \mathrm{MPa}$ at slightly higher $w=6.13-9.36 \%$. The average dry density of the pellets at this hydraulic condition was $\rho_{d \text { pell }}=1.99 \mathrm{Mg} / \mathrm{m}^{3}$ (void ratio $e=0.392$, porosity $n=0.282$ and degree of saturation $S_{r}$ between 0.433 and 0.661 ). The quasispherical pellets presented $D_{P e}=7 \mathrm{~mm}$ in diameter.

Table 1. Properties of MX-80 bentonite and different active clays.

\begin{tabular}{|c|c|c|c|}
\hline Properties & MX-80 & Febex $^{\text {b }}$ & FoCa Clay $^{\mathbf{c}}$ \\
\hline Liquid limit & $420-560 \%$ & $102 \%$ & $112 \%$ \\
\hline Plastic limit & $62 \%$ & $53 \%$ & $34 \%$ \\
\hline $\begin{array}{c}\text { Density of } \\
\text { particles, } \rho_{s}{ }^{\text {a }}\end{array}$ & $2.77 \mathrm{Mg} / \mathrm{m}^{3}$ & $2.70 \mathrm{Mg} / \mathrm{m}^{3}$ & $2.67 \mathrm{Mg} / \mathrm{m}^{3}$ \\
\hline
\end{tabular}

$\mathrm{a}[5]^{\mathrm{b}}[4] \mathrm{c}[6]$

The powder was fabricated by crushing pellets with a maximum particle size $D_{P o}=4.75 \mathrm{~mm}$. The initial total suction displayed a value $s=82 \mathrm{MPa}$ at $w=9.51 \%(w$ varied between $9.51 \%$ and $10.64 \%$ ). The dry density of the poured powder was estimated by placing it in layers using different procedures -with some vibration and without vibration. The selected dry density of the powder was the one without vibration $\rho_{d}$ pow $=1.10 \mathrm{Mg} / \mathrm{m}^{3}\left(e=1.52, S_{r}\right.$ between 0.173 and 0.194$)$. Figure 1a shows the packing of pellets, and Figure $1 \mathrm{~b}$ the mixture of pellets/powder.
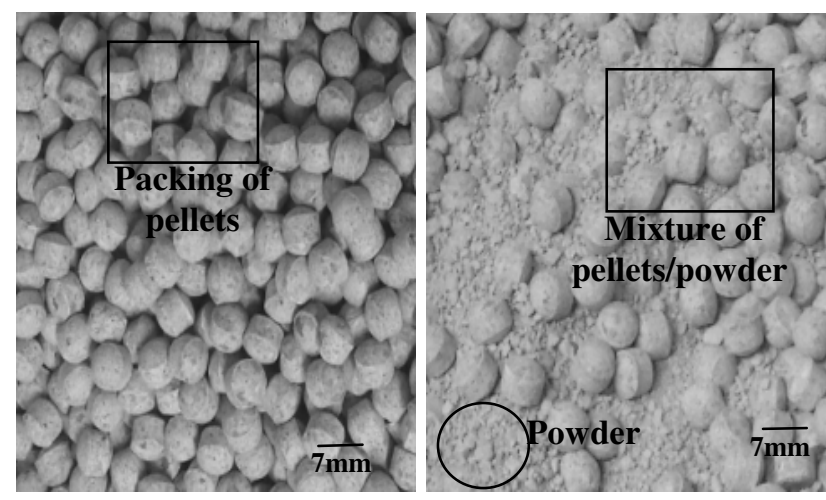

Fig. 1. a) Packing of pellets with spherical caps with diameter $7 \mathrm{~mm}$ and height $7 \mathrm{~mm}$; and b) mixture of pellets and powder.

Table 2 presents the dry density (void ratio and porosity) of different configurations of packing of pellets (skeleton of pellets without powder). The table includes theoretical arrangements of spheres (simple cubic and cubical-tetrahedral), as well as the ones arranged in the laboratory by placing quasi-spheroidal pellets on a known volume. The dry density of the packing of pellets varied from 1.11 to $1.19 \mathrm{Mg} / \mathrm{m}^{3}$, corresponding to configurations between simple cubic (coordination number 6) and cubical-tetrahedral (coordination number $8)$. The latter one is the configuration that is intended to be reached when placing the mixture and that cannot be efficiently achieved by merely pouring the pellets.

Mixtures of these pellets ( $80 \%$ by dry mass) and powder were prepared for the study. If the packing of pellets is first placed to ensure a coordination number close to $8\left(\rho_{d \text { pell }}^{\text {pack }}=1.19 \mathrm{Mg} / \mathrm{m}^{3}\right)$, and powder with a dry mass fraction $f=0.20$ is then poured (partially filling the inter-pellet pores), the dry density of the mixture is obtained as

$$
\rho_{d m i x}=\frac{1}{1-f} \rho_{d p e l l}^{\text {pack }}=1.49 \mathrm{Mg} / \mathrm{m}^{3}
$$

The minimum dry density of the powder $\rho_{d \text { pow }}^{\min }$ with mass fraction $f=0.20$ to fill all the inter-pellet porosity ( $n=0.442$ in Table 2 for the pellet arrangement in the laboratory) is given by Equation (2). This minimum dry density allowed determining the volumetric degree of powder filling $F$, assuming a poured powder dry density $\rho_{\text {d pow }}=1.10 \mathrm{Mg} / \mathrm{m}^{3}$.

$$
\begin{aligned}
& \rho_{d \text { pow }}^{\min }=\frac{f}{n} \rho_{d \text { mix }}=\frac{0.20}{0.442} \times 1.49 \mathrm{Mg} / \mathrm{m}^{3} \\
& \rho_{d \text { pow }}^{\min }=0.67 \mathrm{Mg} / \mathrm{m}^{3} \\
& F=\frac{\rho_{d \text { pow }}^{\text {min }}}{\rho_{d \text { pow }}}=0.61
\end{aligned}
$$

Table 2. Properties of packing of pellets.

\begin{tabular}{|c|c|c|c|}
\hline $\begin{array}{c}\text { Packing } \\
\text { (coordination } \\
\text { number) }\end{array}$ & $\begin{array}{c}\text { Dry density } \\
\text { of packing } \\
\left(\mathbf{M g} / \mathbf{m}^{\mathbf{3}}\right)\end{array}$ & $\begin{array}{c}\text { Inter-pellet } \\
\text { porosity }\end{array}$ & $\begin{array}{c}\text { Inter-pellet } \\
\text { void ratio }\end{array}$ \\
\hline $\begin{array}{c}\text { Simple } \\
\text { cubic (6) }\end{array}$ & 1.04 & 0.476 & 0.908 \\
\hline $\begin{array}{c}\text { Cubical- } \\
\text { tetrahedral (8) }\end{array}$ & 1.20 & 0.395 & 0.653 \\
\hline $\begin{array}{c}\text { Arrangements } \\
\text { in laboratory }\end{array}$ & $1.11-1.19$ & $0.442-0.402$ & $0.793-0.672$ \\
\hline
\end{tabular}

Figure 2 shows the particle size distribution of the different components and the mixture. Particle size distributions of fine MX- 80 bentonite obtained by sedimentation and laser granulometry are also plotted for reference [3].

It is important to check the possibility of powder movement during pouring through the large inter-pellet voids. Pellets are arranged before, and then the powder is poured over the packing of pellets to ensure the target dry density of the mixture [8]. The expected inter-pellet void size is around $0.30 D_{P e}=2.1 \mathrm{~mm}$ (see for instance, [9]). Since maximum powder grain sizes $D_{P o}$ are larger than $0.30 D_{P e}$ (see Figure 2) no important movements of powder within the pellet skeleton are expected, and no significant segregation effects will develop on powder pouring. This fact has been verified by [8] during the installation of the mixture in a large hydration column. 


\section{Pore size distributions of the components}

A microstructural characterisation focused on the pore size distribution with mercury intrusion porosimetry MIP (Micrometrics Auto Pore IV 9500) was performed on freeze-dried pellet and powder at two hydraulic states. Washburn equation (at the top of Equation (3)) was used to provide a relationship between the applied (absolute) non-wetting mercury pressure $p$, and the entrance pore size $x\left(\sigma_{n w}=0.484 \mathrm{~N} / \mathrm{m}\right.$ at $25^{\circ} \mathrm{C}$ is the surface tension of non-wetting mercury, and $\theta_{n w}=140^{\circ}$ the contact angle between mercury and particle surface). The pore size density PSD function [10] was determined using Equation (3) at the bottom ( $e_{\text {int }}$ represents the intruded void ratio, volume of intruded mercury to the volume of solids).

$$
\begin{aligned}
& p=-\frac{4 \sigma_{n w} \cos \theta_{n w}}{x} \\
& f(\log x)=-\frac{\mathrm{d} e_{i n t}}{\mathrm{~d} \log x}
\end{aligned}
$$

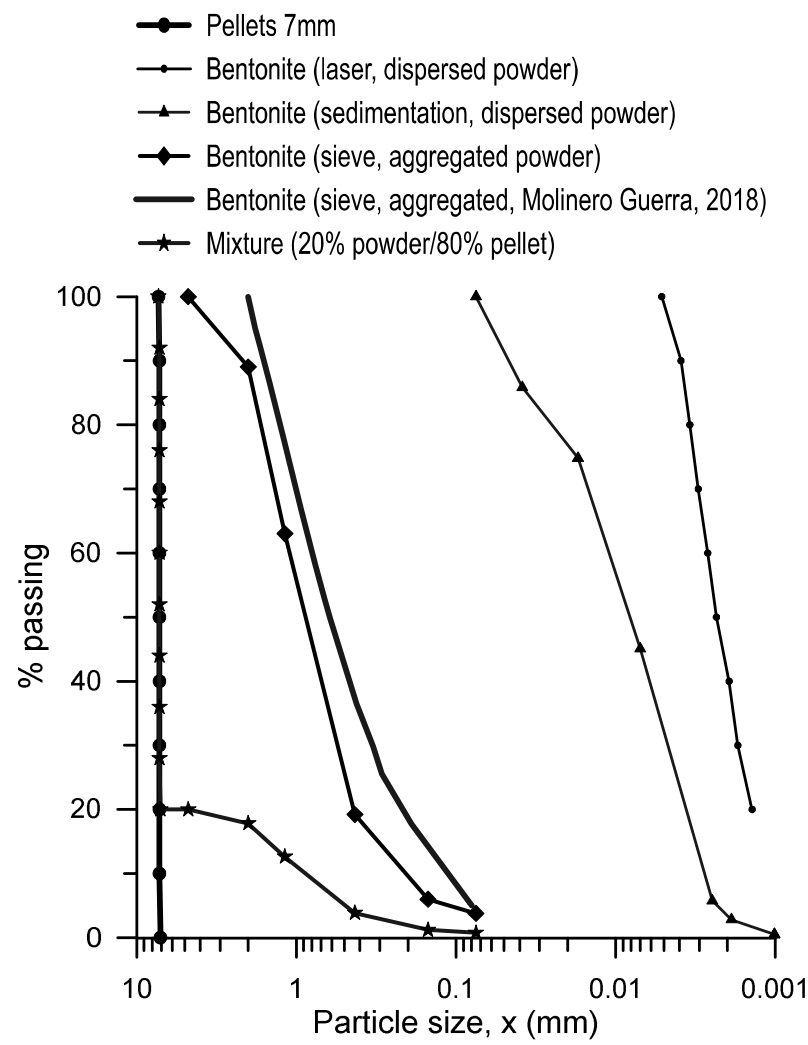

Fig. 2. Particle size distributions of pellet, granulated powder and mixture, as well as for fine MX-80 by sedimentation/laser.

Figure 3 shows the PSD function of the ascompacted pellet $(e=0.454)$, which displays two dominant pore modes at approximately $20 \mathrm{~nm}$ (micropores) and between $10 \mu \mathrm{m}$ and $20 \mu \mathrm{m}$ (macropores between aggregates and fissures). A value of $1 \mu \mathrm{m}$ was considered to separate these two pore domains inside the pellet $[2,11,12]$. The PSD of a saturated pellet has also been plotted, which was retrieved from a saturated packing of pellets that was soaked under constant volume conditions ( $\rho_{d \text { pell }}^{\text {pack }}$ $\left.=1.19 \mathrm{Mg} / \mathrm{m}^{3}\right)$. Therefore, the pellets were not undergoing constant volume conditions on soaking. As observed, the pore network underwent significant changes during saturation, in which the saturated PSD function of the pellet displayed a dominant pore mode at around $2.5 \mu \mathrm{m}$. The figure also incorporates the difference between the final and initial PSD functions, which indicate an evident pore volume decrease at interaggregate scale $(>10 \mu \mathrm{m})$ and a significant pore volume increase between $200 \mathrm{~nm}$ and $10 \mu \mathrm{m}$.

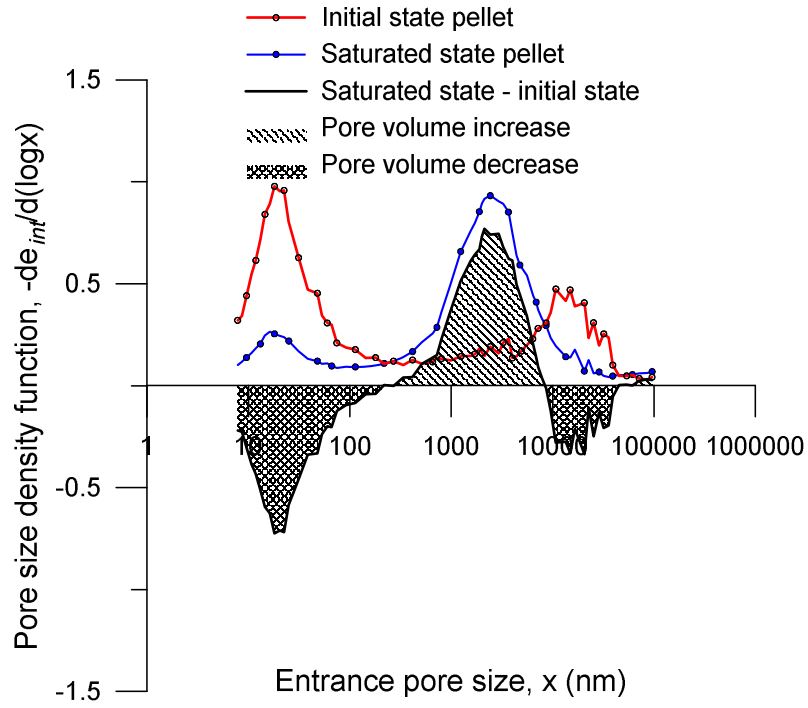

Fig. 3. PSD functions of the pellet at different hydraulic states (as-compacted and saturated).

Figure 4 shows the equivalent PSD functions of the bentonite powder at as-poured and saturated states. The as-poured material displays two dominant pore modes at $20 \mathrm{~nm}$ and between $169 \mu \mathrm{m}$ and $187 \mu \mathrm{m}$. Power compaction, to prepare pellets, was mainly associated with a reduction of the macropores and its dominant pore size. The same value of $1 \mu \mathrm{m}$ was considered to separate the pore domains of the powder. This double pore network changes during saturation at constant volume conditions, displaying the PSD function a dominant pore mode at around $0.5 \mu \mathrm{m}$ for the saturated powder. The figure also includes the difference between the final and initial PSD functions, which again indicate an evident pore volume decrease at inter-aggregate scale $(>10 \mu \mathrm{m})$ and a significant pore volume increase between $70 \mathrm{~nm}$ and $10 \mu \mathrm{m}$.

Table 3 summarises the microstructural characterisation at the different hydraulic states of the pellet and the powder. The second column presents the intruded void ratio $e_{i n t}$ by MIP. $e_{i n t}$ is usually smaller than the real void ratio $e$ (first column) due to the nonintruded void ratio with pore sizes below $7 \mathrm{~nm}$ and the non-detected void ratio with pore sizes above $400 \mu \mathrm{m}$ [10]. This smaller $e_{i n t}$ compared to $e$ is consistent for powder at both hydraulic states and the saturated pellet. It is not the case of the dry pellet due to some intruded pore volume associated with fissures. 
The measured microstructural void ratio $e_{m}$ (with pore sizes smaller than $1 \mu \mathrm{m}$ ) to the total intruded void ratio $e_{i n t}$ was determined with the following expression $\left(x_{\min }=7 \mathrm{~nm}\right.$ and $x_{\max }=400 \mu \mathrm{m}$ refer to the minimum and maximum pore sizes detected by MIP):

$$
\frac{e_{m}}{e_{i n t}}=\frac{\int_{x_{\min }}^{x=1 \mu \mathrm{m}} f(\log x) \mathrm{d} \log x}{\int_{x_{\min }}^{x_{\max }} f(\log x) \mathrm{d} \log x}
$$

The ratios given by Equation (4) and shown in the third column were then multiplied by the real void ratios $e$ of the different states to estimate the corresponding microstructural void ratios $e_{m}$ (fourth column). The macrostructural void ratios with sizes larger than $1 \mu \mathrm{m}$ were finally calculated as $e_{M}=e-e_{m}$ (the fifth column).

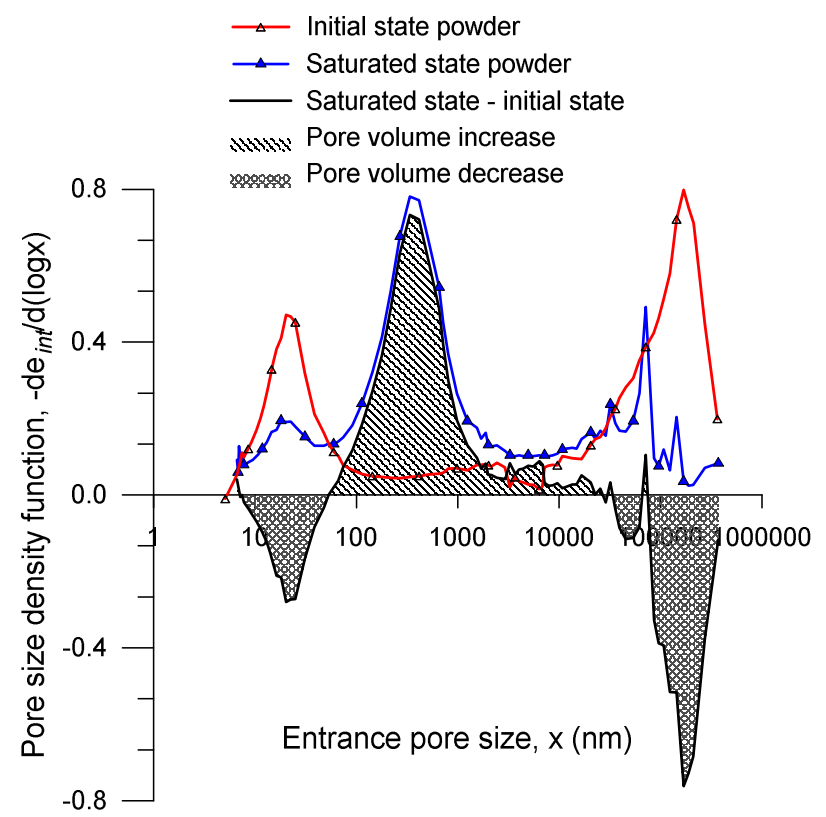

Fig. 4. PSD functions of powder at different hydraulic states (as-poured and saturated).

As observed, $e_{m}$ significantly increased with water content. The parameter $\beta$ that describes the change in $e_{m}$ for a water ratio $e_{w}$ change (volume of water to the volume of solids) is given by:

$$
\beta=\frac{\Delta e_{m}}{\Delta e_{w}} \text { with } e_{w}=\frac{\rho_{s}}{\rho_{w}} w
$$

Table 3 also presents the different $\beta$ for the powder and the pellet undergoing saturation. The values are consistent with data reported by [12], ranging between $\beta=0.40$ and 0.43 for clays with a high content of montmorillonite. The microstructural void ratios for each component $\left(e_{m P o}\right.$ and $e_{m P e}$, for the powder and the pellet, respectively) were used to estimate the corresponding values $e_{m}$ for the mixture at the two hydraulic states:

$$
e_{m}=\frac{V_{p}^{m}}{V_{s}}=e_{m P o} f+e_{m P e}(1-f)
$$

where $f=0.20$ is the dry mass fraction of the powder (equivalent to the fraction of the volume of solids of the powder to the total volume of solids $V_{s}$ of the mixture) and $V_{p}^{m}$ is the volume of micropores (powder and pellets). Table 4 presents $e_{m}$ values for the mixture at two hydraulic states based on the microstructural information of the components.

\begin{tabular}{|c|c|c|c|c|c|}
\hline Component & $\begin{array}{c}\boldsymbol{e}_{i n t} \\
(\mathbf{M I P})\end{array}$ & $\begin{array}{l}e_{m} / e_{i n t} \\
(\mathrm{MIP})\end{array}$ & $e_{m}$ & $e_{M}$ & $\beta$ \\
\hline 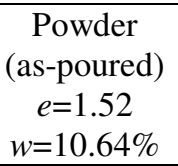 & 0.879 & 0.349 & 0.530 & 0.990 & \multirow[b]{2}{*}{0.440} \\
\hline $\begin{array}{c}\text { Powder } \\
\text { (isochoric } \\
\text { saturation) } \\
e=1.52 \\
w=54.95 \%\end{array}$ & 1.01 & 0.706 & 1.07 & 0.450 & \\
\hline $\begin{array}{c}\text { Pellet (as- } \\
\text { compacted) } \\
e=0.392 \\
w=6.54 \%\end{array}$ & 0.454 & 0.654 & 0.256 & 0.136 & \multirow{2}{*}{0.331} \\
\hline $\begin{array}{c}\text { Pellet } \\
\text { (saturated) } \\
e=1.33 \\
w=41.16 \%\end{array}$ & 1.08 & 0.431 & 0.573 & 0.757 & \\
\hline
\end{tabular}

Table 3. Micro and macrostructural void ratios for the different components at different hydraulic states.

The micro and macrostructural porosities, $n_{m}$ and $n_{M}$, respectively, were also determined for the mixture at the two hydraulic states (as-prepared and saturated). These variables are useful for double porosity approaches and pellet representation models as those implemented in the fully-coupled HM finite element program Code-Bright [8].

$$
\begin{gathered}
\bar{n}_{m}=\frac{V_{p}^{m}}{V_{s}+V_{p}^{m}}=\frac{e_{m}}{1+e_{m}} ; n_{M}=\frac{V_{p}^{M}}{V_{t}} \\
n_{m}=\frac{V_{p}^{m}}{V_{t}}=\bar{n}_{m}\left(1-n_{M}\right) ; n=n_{M}+n_{m}
\end{gathered}
$$

where $V_{p}^{m}$ is the volume of micropores previously defined and $V_{p}^{M}=V_{p}-V_{p}^{m}$ the volume of macropores. Table 4 summarises these microstructural variables for the mixture (the saturation path was performed under constant volume conditions). As observed, $n_{m}$ increased with saturation and significantly reduced $n_{M}$. 


\section{Hydraulic and compressibility properties of the components and the mixture}

\subsection{Water retention properties}

Figure 5 shows the water retention curve of the powder on wetting and in terms of water content starting from $s$ $=82 \mathrm{MPa}$ at $w=9.51 \%$. Total suctions after water addition and equalisation were measured with WP4 chilled-mirror dewpoint psychrometer. The figure also presents the estimated water retention curve of the pellet using MIP data. The non-wetting mercury penetration is assumed to be equivalent to air-intrusion path for the same diameter of pores being intruded [10]. The wetting path results of the mixture from [3] have also been included, together with data at different void ratios from other authors $[3,7]$. At water contents $w<10 \%$ the water retention curves merge and are not sensitive to void ratio [13]. Experimental data were fitted to the following expression [14]

$$
S_{r}=\frac{w}{w_{\text {sat }}}=\left[1+\left(\frac{s}{P_{0}}\right)^{\frac{1}{1-\lambda}}\right]^{-\lambda}
$$

The same parameter $\lambda=0.32$ was used for the components and the mixture. $P_{0}$ values were $35 \mathrm{MPa}$, $10 \mathrm{MPa}$ and $2 \mathrm{MPa}$ for the pellet, mixture and powder, respectively.

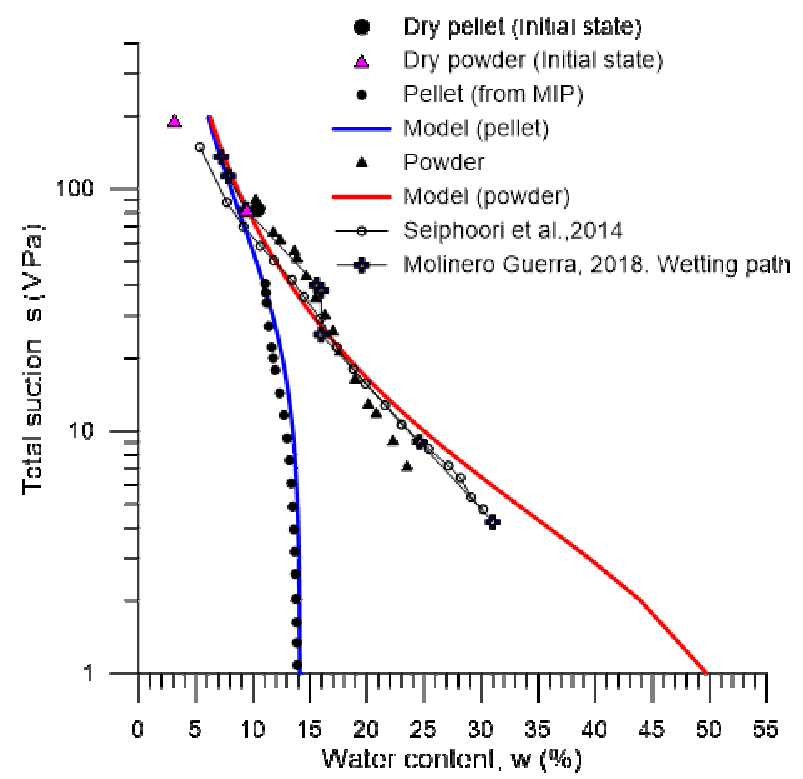

Fig. 5. Water retention curves for the components and the mixture. Data on MX-80 from different authors.
Table 4. Microstructural variables for the mixture at two hydraulic states using Equations (6) and (7).

\begin{tabular}{|c|c|c|c|c|}
\hline Hydraulic state & $\boldsymbol{e}_{\boldsymbol{m}}$ & $\bar{n}_{m}$ & $\boldsymbol{n}_{\boldsymbol{M}}$ & $\boldsymbol{n}_{\boldsymbol{m}}$ \\
\hline $\begin{array}{c}\text { As-prepared } \\
n=0.462 w=8.47 \%\end{array}$ & 0.311 & 0.237 & 0.295 & 0.167 \\
\hline $\begin{array}{c}\text { Saturated } \\
n=0.462 w=31.0 \%\end{array}$ & 0.672 & 0.402 & 0.100 & 0.362 \\
\hline
\end{tabular}

\subsection{Water permeability}

Long-term saturation tests were carried on powder and mixture under constant volume conditions (samples 50 $\mathrm{mm}$ in diameter and $20 \mathrm{~mm}$ high). The initial water contents were $w=7.66 \%$ (total suction $s=111 \mathrm{MPa}$ ) and $w=9.51 \%(s=82 \mathrm{MPa})$ for the mixture and powder, respectively. The final values reached were $w=$ $30.93 \%\left(S_{r}=0.97\right)$ for the mixture and $w=54.95 \%\left(S_{r}=\right.$ $1)$ for the powder. The water permeability was measured under controlled-gradient conditions. Intrinsic permeabilities of $5.64 \times 10^{-20} \mathrm{~m}^{2}$ for powder and $1.17 \times 10^{-}$ ${ }^{20} \mathrm{~m}^{2}$ for the mixture were measured. The intrinsic permeability of the pellet was estimated using MIP data considering the Hagen-Poiseuille equation for laminar flow through cylindrical tubes of diameter $x$ [13], according to the following expression:

$$
K_{P e}=\alpha n_{i n t} \int_{x_{\min }}^{x_{\max }} x^{2} f(x) \mathrm{d} x=1.6 \times 10^{-21} \mathrm{~m}^{2}
$$

where $n_{\text {int }}=0.312$ is the intruded porosity, $x$ the pore size, and $f(x)$ the pore size density function $\left(x_{\min }=7 \mathrm{~nm}\right.$ and $x_{\max }=400 \mu \mathrm{m}$ refer to the minimum and maximum pore sizes detected by MIP). Parameter $\alpha=8.2 \times 10^{-12}$, which takes into account the shape factor, tortuosity and connectivity, was fitted with the measured intrinsic permeability and pore size distribution of the dry powder $\left(n_{\text {int }}=0.468\right)$. Intrinsic permeability results are shown in Figure 6 as a function of porosity. Data reported by different authors [15-17] on MX-80 have also been plotted. The results have been fitted with the KozenyCarman equation

$$
\begin{aligned}
& K=K_{0} \frac{f(n)}{f\left(n_{0}\right)} \text { with } f(n)=\frac{n^{3}}{(1-n)^{2}} \\
& K_{0}=2 \times 10^{-21} \mathrm{~m}^{2} \text { and } n_{0}=0.30
\end{aligned}
$$




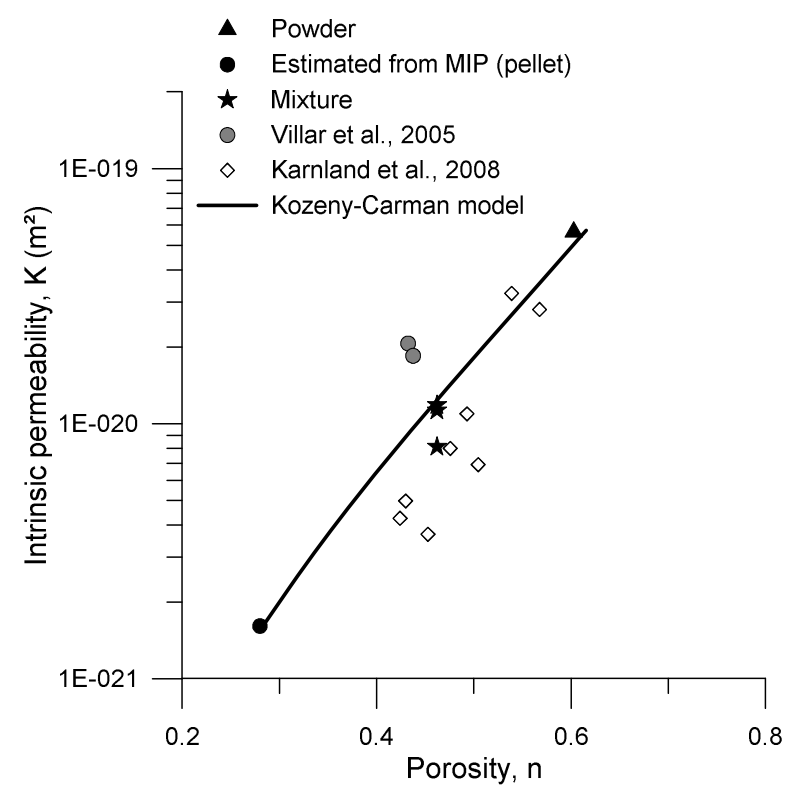

Fig. 6. Water permeability results as a function of porosity for the different components. Fitted curve with Kozeny-Carman equation.

\subsection{Compressibility properties on loading}

Different oedometer tests $(50 \mathrm{~mm}$ in diameter and 20 $\mathrm{mm}$ high) at constant water content were performed on the components and the mixture: powder at an initial $e$ $=1.52$ and $s=85 \mathrm{MPa}$; compacted powder at an initial $e=0.385$ and $s=88 \mathrm{MPa}$ (representing the pellet); and mixture at an initial $e=0.884$ and $s=108 \mathrm{MPa}$. Figure 7 presents the compression curves on loading/unloading. As expected, the powder displayed the highest post-yield compressibility $\lambda(s)=-\mathrm{d} e / \mathrm{d} \ln \sigma_{v}=0.27$. The mixture presented $\lambda(s)=0.13$ due to the higher stiffness of the pellet skeleton. The yield stress of the powder was around $0.8-0.9 \mathrm{MPa}$, whereas about $1.5 \mathrm{MPa}$ in the mixture.

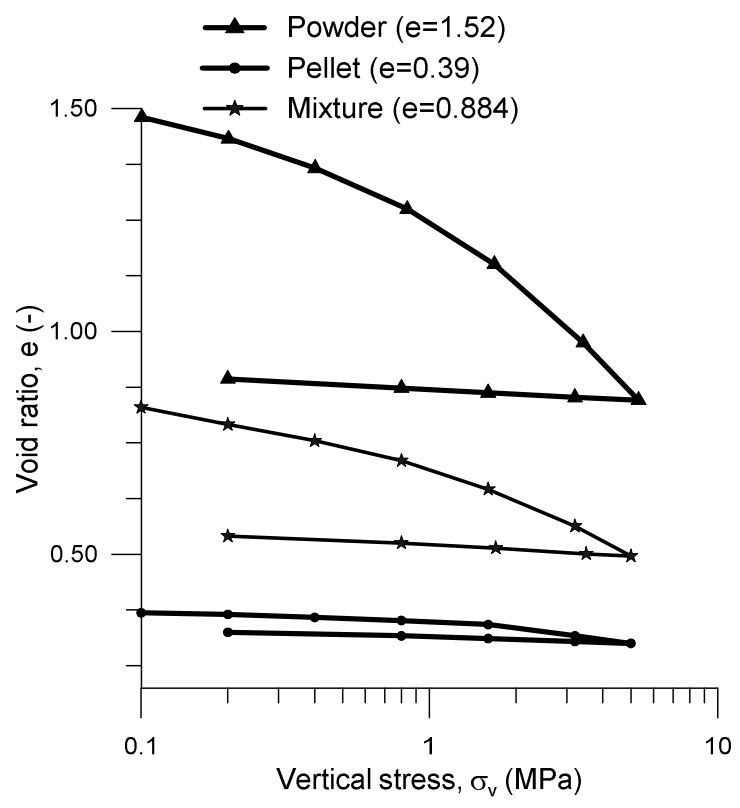

Fig. 7. Compression behaviour on loading/unloading of powder, pellet and mixture at constant water content.

\section{Concluding remarks}

The paper presented an experimental study on a binary mixture of MX80 bentonite pellets (80\% in mass) and powder. The study focused on characterising the initial state, the pore size distribution PSD with mercury intrusion porosimetry MIP, as well as selected hydromechanical properties for both components (pellets and powder) and the mixture. The components and the mixture displayed multi-modal PSDs that significantly changed during saturation. The microstructural void ratio (volume of pores $\leq 1 \mu \mathrm{m}$ to the total volume of solids) was used to quantify these consistent PSD changes.

The water retention results in terms of water contents indicated that at water contents $<10 \%$ the water retention curves of the components were not sensitive to void ratio. The water permeability of the powder and mixture were measured under controlled-gradient conditions. In contrast, the intrinsic permeability of the pellet was estimated MIP data interpreted with HagenPoiseuille equation. The consistent permeability results were fitted to a unique Kozeny-Carman equation depending on porosity. Regarding compressibility on loading of the components and the mixture, the results also showed consistent results. These results are useful to study the local and global hydro-mechanical behaviour of the mixture using a finite element coupled program based on the discretisation of pellets and powder [8].

\section{Acknowledgements}

The authors wish to acknowledge the financial support of 'Institut de Radioprotection et de Sûreté Nucléaire' IRSN (France) through a PhD collaboration agreement with CIMNE (Spain) within the context of the VSEAL Project 'Long-term performance of vertical sealing systems and impact of gas migration' (2016-2020).

\section{References}

1. A. Gens, M. Sánchez, B. Valleján, C. Imbert, M. V. Villar, and M. Van Geet, Géotechnique 61, 367 (2011).

2. E. E. Alonso, E. Romero, and C. Hoffmann, Géotechnique 61, 329 (2011).

3. A. Molinero Guerra, Caractérisations Expérimentale et Numérique Du Comportement Hydro- Mécanique d' Un Matériau Hétérogène: Mélange de Poudre / Pellets de Bentonite Doctor of Univers, Université Paris-Est, 2018.

4. M. V. Villar, Caracterización Termo-HidroMecánica de Una Bentonita de Cabo de Gata, Ph.D. Thesis. Universidad Complutense de Madrid. 387 pp. Madrid, 2000.

5. S. Saba, Doctoral Thesis: Hydro-Mechanical Behaviour of Bentonite-Sand Mixture Used as Sealing Materials in Radioactive Waste, Université Paris-Est, 2014. 
6. C. Imbert, J.-M. Fleureau, S. Kheirbek-Saoud, and L. \& Deprez, Caracterisation Hydrique Des Materiaux de l'experience PRACLAY (FontenayAux-Roses, France. Commissariat A' l'energie Atomique (CEA), Technical Report (in French)., 1997).

7. A. Seiphoori, A. Ferrari, and L. Laloui, Géotechnique 64, 721 (2014).

8. A. Mesa-Alcantara, Hydro-Mechanical Behaviour of Binary Pelletized Mixtures of Bentonite and Impact of Gas Migration., Universitat Politècnica de Catalunya, n.d.

9. K. Kamiya and T. Uno, Unsaturated Soils Asia. Proc. Asian Conf. Unsaturated Soils, UNSAT-ASIA 2000, Singapore, 18-19 May, 2000399 (2000).

10. E. Romero and P. H. Simms, Geotech. Geol. Eng. 26, 705 (2008).

11. E. Romero, G. Della Vecchia, and C. Jommi, Géotechnique 61, 313 (2011).

12. E. Romero, Eng. Geol. 165, 3 (2013).

13. E. Romero, A. Gens, and A. Lloret, Eng. Geol. 54, 117 (1999).

14. M. T. van Genuchten., Soil Sci. Soc. Am. J. J. 44, 892 (1980).

15. M. V. Villar, Bentonita MX-80. Caracterización Termo-Hidro-Mecánica Realizada En CIEMAT En El Contexto Del Proyecto Prototype (CIEMAT Technical Report 1053. CIEMAT, Madrid, Spain. 39 Pp., 2005).

16. L. Gonzalez-Blanco, E. Romero, C. Jommi, X. Sillen, and X. Li, Springer Int. Publ. (2017).

17. O. Karnland, U. Nilsson, H. Weber, and P. Wersin, Phys. Chem. Earth, Parts A/B/C 33, S472 (2008). 